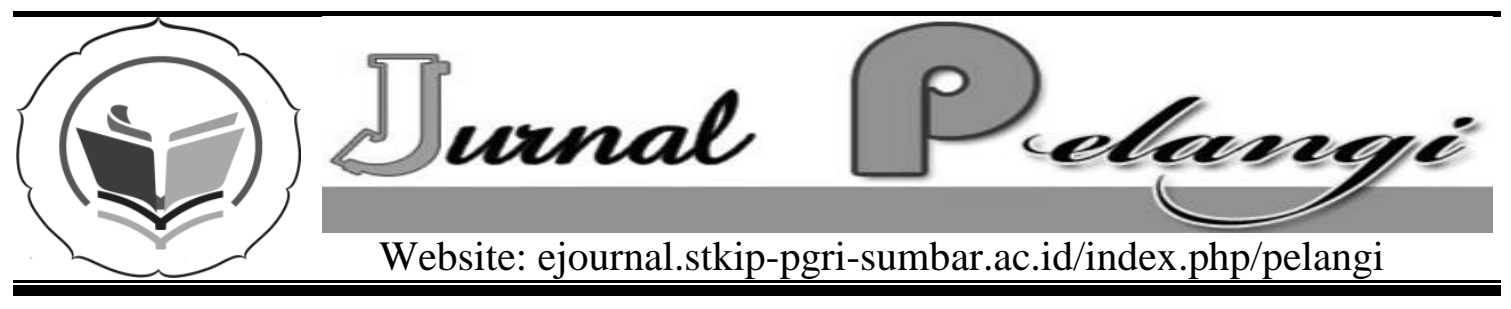

\title{
KOMUNIKASI PESERTA DIDIK YANG TERISOLIR DAN POPULER DI SMU X KOTA PADANG
}

Gusneli

STKIP PGRI Sumatera Barat

gusneli@yahoo.com

INFO ARTIKEL

Diterima: 5 Mei 2015

Disetujui: 22 Juni 2015

Kata Kunci:

Komunikasi, peserta didik terisolir populer
Keywords:

Communication, Isolation And Popularity of Student

\section{Abstrak}

Penelitian ini bertujuan untuk mendeskripsikan karakteristik komunikasi peserta didik SMU yang terisolir dan populer. Untuk itu, digunakan pendekatan kualitatif deskriptif. Pengumpulan data dilakukan dengan menggunakan teknik observasi, sosiometri, wawancara, dan studi dokumentasi. Keabsahan data diuji melalui wawancara dengan beberapa informan yaitu teman subyek dan guru BK serta pengamatan dan wawancara yang dilakukan oleh peneliti dan beberapa orang pembantu peneliti. Hasil penelitian ini menunjukkan bahwa keterisolasian dan kepopuleran peserta didik di dalam lingkungan sosialnya terutama di sekolah, tidak terlepas dari peran teman-temannya dan komunikasi peserta didik di dalam kelas, hal yang berperan sangat besar adalah keadaan internal peserta didik dalam merespon lingkungan sosialnya.

\section{Abstract}

This research aims to describe the characteristics of senior hight school communication isolation and popularity of student. In order to obtain the purpose, qualitative approach was applied. The data of the research were collected by applying such techniques as observation, sociometric, interview, and documentary studies. To check data truthworthiness, trianggulation technique was aplied in wich interview with several classmates of subjects of the reasearch and observation besaid interview and observation were done by co-researcher from the information obtainerd.The result of the research shows shat such isolation and popularity of student in this/her social environtment, aspecially in the school cannot be apart from the result from this dealing with the classmate during classroom communication. Above all, the later has greater responsibility for the subject's internal 



\section{PENDAHULUAN}

Komunikasi merupakan cara bagi individu untuk mengembangkan hubungan dengan orang lain. Melalui komunikasi individu dapat saling bertukar informasi, membangun kontak sosial, dan dapat juga mempengaruhi orang lain dalam berpikir, merasa, dan berperilaku sesuai dengan yang diinginkan.

Kondisi personal dan faktor situasional memberikan kontribusi yang besar pada diri individu dalam mempersepsi suatu situasi. Persepsi individu dapat mempengaruhi sikap, yaitu bagaimana kesiapan individu untuk bertindak, yang akan mengarah pada munculnya perilaku tertentu. Persepsi, sikap, dan perilaku biasanya konsisten. Jika individu mempunyai persepsi negatif pada seseorang, maka orang tersebut akan merasa tidak nyaman ketika bertemu, sehingga akan mencoba untuk menghindar ketika bertemu. Tidak semua persepsi, sikap, dan perilaku itu konsisten. Untuk menjaga sopan santun walaupun seseorang tidak menyukai orang lain, tapi mereka tetap mencoba untuk ramah.

Dalam proses komunikasi adakalanya individu gagal menyampaikan pesan atau pesan yang disampaikan tidak dapat diterima oleh orang lain sebagaimana mestinya, akibatnya muncul kesalahpahaman, yang berujung konflik. Kondisi seperti ini dapat ditemui di sekolah, khususnya komunikasi antara peserta didik dengan teman-temannya. Melalui para guru sebagai pelaksana pendidikan, khususnya guru BK kondisi seperti ini dapat dicegah dan diatasi.

\section{METODOLOGI PENELITIAN}

Penelitian ini dilakukan di sebuah SMU di Kota Padang, dengan menggunakan metode penelitian kualitatif deskriptif. Untuk memperoleh subjek penelitian terlebih dahulu digunakan sosiometri. Dari hasil sosiometri ditetapkan dua orang peserta didik terisolir dan dua orang peserta didik yang populer sebagai informan kunci. Dan sebagai informan tambahan adalah kawan-kawan yang dekat dengan mereka, guru BK, wali kelas, dan guru mata pelajaran. Untuk memperoleh data dilakukan observasi dan wawancara dengan informan kunci dan informan tambahan.

\section{HASIL DAN PEMBAHASAN}

\section{Komunikasi di dalam kelas}

Berdasarkan hasil penelitian, komunikasi peserta didik terisolir dan populer berbeda. Perbedaan dapat terlihat dari kuantitas komunikasi mereka dengan kawan-kawan dan ekspresi wajah mereka saat berkomunikasi. Komunikasi peserta didik terisolir Rani misalnya, ia jarang berbicara dengan kawan-kawan di kelasnya, kalaupun berbicara ia memperlihatkan ekspresi wajah yang tidak bersemangat dan jarang tersenyum. Sappington (Mueser:1984) mengatakan "People who are smilling are usually reted as more attractive than people who aren't smilling, evenreters are told to compensate for the impact of smile." Ekspresi wajah dan sikap yang sering ditampilkan oleh Rani saat berkomunikasi tidak dapat membuat kawan tertarik padanya, malahan mengirimkan pesan kepada kawankawannya bahwa ia tidak merasa senang 
dan enggan berkomunikasi dengan mereka. Akibatnya kawan-kawan menjauhinya.

Peserta didik terisolir lainnya adalah Romi. Romi adalah peserta didik yang sangat pendiam dan kurang mampu melakukan komunikasi yang baik. Menurut Sappington (1989:325) "All relationships depend upon communication, but intimate relationships depend upon a special type of communication of information about ourselves. The process of revealing information about yourself to another person is called self-disclosure".

Karena sifatnya yang pendiam, kurang mampu mengungkapkan diri sendiri. Dengan kekurangmampuan berkomunikasi tidak memungkinkan Romi untuk bisa terbuka dengan orang lain dan melindungi dirinya dari olokolok kawan-kawannya. Untuk menghindarinya ia berusaha menarik diri dari lingkungan sosialnya yang ia rasakan kurang bersahabat, ditambah lagi dengan rasa rendah diri membuat dirinya semakin terpuruk dalam kesendirian. Dalam kesendirian Romi merasa lebih aman, nyaman, dan bebas.

Sebenarnya Romi ingin meluapkan kemarahan karena diperolok, tapi ia tidak mampu melakukannya. Ia tidak mampu mengkomunikasikan kemarahannya, baik dengan kata-kata maupun dengan cara lain. Semua kemarahan dan rasa malunya dia tekan dan tanggungkan sendiri tanpa mau berbagi dengan orang lain, sehingga penampilan wajahnya tampak kusut: dan mungkin itulah yang membuat wajahnya tampak tua.

Sifat tidak mau berbagi (pelit) dalam berkomunikasi, atau berbagi perasaan dan pengalaman (termasuk pelajaran) ini dapat merupakan salah satu cara membentengi dirinya dan menunjukkan keunggulannya dari kawan-kawan yang lain. Tidak mau berbagi merupakan harga dirinnya yang ingin diperlihatkan kepada kawan-kawan yang suka mengganggu dan memperoloknya. Romi merasakan sedikit rasa puas bila dapat mengabaikan permintaan mereka.

Sementara Peserta didik populer sering berkomunikasi dengan kawankawannya. Rahmah misalnya, pada umumnya di kelas kalau tidak membicarakan hal-hal yang serius Rahmah akan bercanda dengan kawankawan atau mendidkusikan pelajaran. Kawan-kawan senang minta bantuan pada Rahmah karena ia dapat menjelaskan pelajaran dengan kalimat yang sederhana sehingga kawan-kawan mudah memahaminya. Kemampuan ini didukung pula ekspresi wajahnya yang menyenangkan dan dapat mengirimkan pesan bahwa ia sangat menyukai kawankawannya. Conger and Farrel (Sappington 1989:324) mengemukakan "People who are seen as socially use many of the elements of SOFTEN. Soften a nonverbal way of exspressing liking or interest: it is an acronym standing for smile, open posture, forward lean, touch, eye contact, and nod".

Kemampuan Rahmah dalam menggunakan elemen-elemen "soften" dalam berkomunikasi membuat Rahmah disenangi oleh kawan-kawannya. Kemampuannnya ini tidak terlepas dari pengalaman masa lalunya. Rahmah dari waktu ke waktu, mau belajar dan selalu memperbaiki cara dia berkomunikasi sehingga dapat memuaskan baik bagi dirinya maupun orang lain.

Peserta didik populer lainnya adalah Teguh. Komunikasi teguh dengan 
kawan-kawannya sering dalam bentuk gurauan yang dapat mengundang tawa atau permintaan dari kawan-kawan untuk menjelaskan materi pelajaran yang kurang mereka pahami. Sifat Teguh yang suka bercanda dan mau membantu membuat teguh sangat disukai oleh kawan-kawan di kelasnya, apalagi kawan perempuan. Kawan-kawan perempuan menyukainya karena tutur katanya yang lembut dan bawaannya yang tenang. Menurut Sappington 1989:317 "Communication is also afoundation for intimate relationships. We cannot establish or maintain genuinely close relationships with others unless we understand something about what they are felling, about what makes them happy or annoyed." Dengan tutur kata yang lembut tersebut kawan-kawan dapat merasa senang, merasa diperhatikan, dan merasa dihargai.

\section{Komunikasi di Luar Kelas}

Komunikasi di luar kelas antara peserta didik terisolir dan populer terdapat perbedaan yang beragam. Perbedaan itu dapat dilihat dari kuantitas komunikasi dan ekspresi wajah mereka ketika berkomunikasi. Rani misalnya: Kuantitas komunikasi antara Rani dengan kawan-kawannya jarang terjadi. Tetapi lain dengan Anggi sahabatnya di kelas lain. Dengan Anggi, Rani sangat sering bercakap-cakap. Hampir setiap jam istirahat mereka pergi bersama. Rani sangat membutuhkan Anggi sebagai tempat curahan hati. Namun persahabatan dengan Anggi pun tampaknya berjalan timpang. Kebutuhan Anggi terhadap Rani tidak sebesar kebutuhan Rani terhadap Anggi. Rani menginginkan persahabatan itu hanya terjalin antara mereka berdua, sementara
Anggi juga membutuhkan sahabatsahabat lainnya. Ada saatnya Anggi berusaha mengelak pertemuan dengan Rani karena ingin berkumpul dengan kawan-kawannya yang lain. Persahabatan seperti ini antara lain dipengaruhi oleh cara dan isi komunikasi Rani dengan Anggi dan kawankawannya.

Sementara komunikasi Romi (peserta didik terisolir) dengan kawankawannya juga jarang terjadi. Hal ini disebabkan karena ia lebih sering suka pergi kemanapun sendiri. Sekali-sekali ia pergi bersama dua orang kawan yang sering duduk sebangku dengannya, namun ia lebih banyak diam. Sikap ini yang mencerminkan kurang lancarnya berkomunikasi, membuat dirinya semakin terasing dari kawan-kawannya.

Komunikasi yang berlangsung melalui olok-olok kawan-kawannya yang ditanggapi Romi dengan perasaan marah, namun dia tetap diam, tidak merespon baik secara verbal maupun non-verbal. Hal ini disebabkan karena ia tidak tahu harus mengatakan atau berbuat apa agar kawan-kawannya berhenti memperoloknya.

Sedangkan komunikasi peserta didik populer di luar kelas sering terjadi. Rahmah misalnya: ia merupakan seorang kawan yang sangat menyenangkan dan mampu menghidupkan suasana. Keceriaannya, tawanya, dan tegur sapanya serta kata-kata yang dilontarkannya mengirimkan pesan yang dirasakan oleh kawan-kawannya sebagai bentuk penghargaan yang tinggi terhadap mereka. Hal ini dapat membangkitkan perasaan bahagia di hati mereka. Perasaan berharga dan kebahagiaan yang dirasakan saat berkomunikasi dengan Rahmah 
menjadikan Rahmah sebagai teman yang sangat dibutuhkan oleh kawankawannya. Apalagi ia selalu bersedia membantu siapa saja yang membutuhkan pertolongannya.

Peserta didik populer lainnya adalah Teguh. Sifat suka membantu kawan adalah salah satu sifat yang menonjol pada Teguh. Apalagi dalam membantu ia tidak pernah membeda-bedakan kawan. Sifat itulah yang membuat ia disukai oleh kawan-kawannya.

Kemampuan menciptakan suasana yang hangat dan menyenangkan di saat jalan-jalan bersama membuat Teguh sering diajak untuk pergi bersama. Namun ia bukanlah orang yang suka berhura-hura. Ia akan langsung bersedia untuk pergi bersama apabila waktunya dianggap tepat. Sikap ini mencerminkan sebuah kepribadian yang sudah mempunyai jati diri, yaitu jati diri yang mampu berkomunikasi, baik sebagai komunikator maupun komunikan.

Komunikasi di dalam kelas dengan guru antara peserta didik terisolir dengan peserta didik populer berbeda. Perbedaan terlihat dari jarang atau seringnya peserta didik bertanya dalam proses belajar mengajar. Pserta didik yang terisolir jarang berkomunikasi dengan guru. Kesempatannya untuk berkomunikasi saat guru menyediakan waktu untuk bertanya bagi yang belum memahami pelajaran tidak dimanfaatkan mereka. Mereka hanya diam dan tidak memberikan respon. Guru tidak mengetahui apakah mereka sudah memahami pelajaran atau belum. Sikap ini sangat merugikan diri mereka sendiri, karena dengan membiarkan diri mereka tidak memahami pelajaran yang dijelaskan guru akan membuat mereka sulit memahami pelajaran berikutnya.
Sebaliknya peserta didik populer sangat rajin bertanya apabila mereka belum memahami pelajaran yang diberikan guru. Hal ini dapat memberikan pengaruh yang positif terhadap kemampuan akademik mereka.

Kuantitas dan kualitas komunikasi antara peserta didik dengan guru di dalam kelas, bila kesempatan itu ada, tidak hanya tergantung pada penguasaan peserta didik terhadap materi yang sedang dibahas dalam pelajaran. Kemampuan berkomunikasi peserta didik juga sangat menentukan. Kurang beraniya menampilkan diri, kurang mampu menyusun kalimat dan menyampaikannya, dan takut disikapi negatif oleh kawan-kawan maupun guru, menghalangi peserta didik yang terisolir untuk berkomunikasi ketika pelajaran berlangsung. Sebaliknya peserta didik yang populer dapat terbebas dari hambatan komunikasi sebagaimana dialami oleh peserta didik terisolir.

Komunikasi dengan guru di luar kelas antara peserta didik terisolir dengan populer juga berbeda. Komunikasi peserta didik terisolir dengan guru hanya ketika mereka berpapasan dalam bentuk tegur sapa. Secara pribadi mereka tidak pernah berkomunikasi dengan guru. Pengenalan guru terhadap mereka hanya sebatas sebagai peserta didik. Para guru tidak mengenal peserta didik terisolir ini secara pribadi, karena mereka jarang sekali atau tidak pernah tampil. Hal ini barangkali diakibatkan oleh perasaan rendah diri dan sifat mereka yang pendiam dan sangat tertutup. Sifat-sifat yang mereka miliki ini tidak memungkinkan mereka untuk bisa dekat dengan guru, apalagi mereka bukanlah peserta didik yang menonjol dalam hal- 
hal tertentu yang akan dapat menerik perhatian guru.

Sebaliknya peserta didik populer Rahmah misalnya: Ia adalah peserta didik yang mempunyai sifat ramah dan sopan. Apabila ia mempunyai kepentingan ia akan menemui guru dengan sopan. Sikapnya yang sopan, tutur katanya yang lancar dan tersusun rapi membuat para guru menyukainya.

Dalam berbagai kegiatan di sekolah Rahmah memberikan kesempatan pada kawan-kawan untuk turut berkembang. Ini merupakan cerminan sikap yang selalu memikirkan orang lain. Sikap inilah yang membuat guru-guru semakin simpati padanya, walaupun ia mampu dan mempunyai kesempatan yang cukup luas menonjolkan kemampuannya dalam banyak bidang. Apalagi ditunjang pula oleh perhatian guru terhadap kemampuannya tersebut.

Rahmah tidak ingin kelihatan domiman. Makanya ia sering menolak apabila diminta guru untuk ikut dalam kegiatan tertentu apabila ia meresa sudah sering terlibat di dalamnya. Hal ini dapat mengkomunikasikan perasaan bahwa ia tidak ingin ada kawan yang merasa iri kepadanya. Karena perasaan iri dapat berkembang dan mengarah pada hal-hal yang bersifat negatif.

Penghargaan Rahma terhadap guru sangat tinggi. Ini terlihat dari keramahannya ketika berpapasan dan menyapa guru atau saat menemui guru apabila ia mempunyai kepentingan di luar kelas.

Peserta didik populer lainnya adalah Teguh. Komunikasi Teguh dengan guru di samping saat bertegur sapa saat bertemu, juga ketika ia mendatangi guru saat ia kurang mengerti dengan apa yang diajarkan, sangat positif. Kadang-kadang
Teguh juga bercanda dengan guru agar merasa lebih dekat. Tidak banyak peserta didik yang mempunyai kemampuan seperti ini. Kebanyakan peserta didik akan segan, ragu atau bahkan tidak mempunyai keberanian untuk menemui guru apabila ia tidak memahami pelajaran yang dijelaskan guru. Tapi lain dengan Teguh ia tidak mempunyai masalah seperti itu.

\section{KESIMPULAN DAN SARAN}

Berdasarkan hasil penelitian dapat disimpulkan bahwa peserta didik terisolir jarang berkomunikasi dengan kawan-kawannya dan memperlihatkan ekspresi yang kurang menyenangkan. Hal inilah yang menyebabkan kawankawan kurang menyukainya. Sedangkan peserta didik yang populer sering berkomunikasi dengan kawan-kawannya dengan ekspresi yang sangat menyenangkan sehingga kawan-kawan merasa nyaman bersama mereka. Peserta didik terisolir jarang berkomunikasi dengan guru karena kurangnya keterampilan komunikasi dan perasaan rendah diri yang berlebihan yang menghalanginya berhubungan dengan orang lain, sedangkan peserta didik populer sering berkomunikasi dengan guru dengan mengajukan pertanyaan pada proses pembelajaran atau jika ada keperluan.

\section{UCAPAN TERIMAKASIH}

Terbitnya tulisan ini tidak terlepas dari bantuan berbagai pihak, untuk itu penulis ucapkan terima kasih yang sebesar-basarnya kepada Pihak STKIP PGRI Sumatera Barat khususnya pengelola jurnal Pelangi yang telah memberikan kesempatan kepada penulis 
untuk menulis dijurnal Pelangi. Selanjutnya penulis juga berterima kasih kepada para penyumbang sumber insirasi yang telah memerikan inspirasi bagi penulis untuk mengutip atau menggunakan tulisannya sebagai bahan referensi.

\section{DAFTAR PUSTAKA}

Bogdan, R \& Biklen. S. (1982) Qualitative Research for Education: An Introduction the Theory and Methods. Boston: Allyn and Bacon.

Carnegie, D. (1993). Bagaimana Mencari Teman dan Mempengaruhi Orang Lain. Jakarta: Binarupa Aksara

Cole, L. (1959). Psychology of Adoleccence. New York: Rinehart and Company.

Deddy Mulyana. 2010. Ilmu Komunikasi: Suatu Pengantar. Bandung: $\quad$ PT. Remaja Rosdakarya.

Jalaludin Rakhmat. 2008. Psikologi Komunikasi. Bandung: PT. Remaja Rosdakarya

Knutson, L Andie (1968). The Individual, Society, and Health Behavior. California: University California.

Miles, Matthew. B \& Huberman. A. Michael (1992). Analisis Data Kualitatif. Jakarta: Universitas Indonesia.

Prayitno, (1994). Dasar-dasar Bimbingan dan Konseling, Jilid I \& II Jakarta: Proyek Pembinaan dan Peningkatan Mutu Tenaga Kependidikan. Dirjen Dikti Departemen Pendidikan dan Kebudayaan.
Sappington, Andrew. A. (1989). Adjusment, Theory Research, and Personal Aplication. California : by Wadsworyh, inc belmont.

Wood, Julia T.(2013). Komunikasi Teori dan Praktik (Komunikasi dalam Kehidupan Kita). Jakarta: Salemba Humanika. 